\title{
The End of Poverty
}

\author{
Jeffrey D. Sachs \\ Special Advisor on MDGs to the UN Secretary-General and Professor of Columbia University
}

\section{Hitting the target}

At the UN's Millennium Assembly in September 2000, the world adopted the Millennium Development Goals (MDGs). quantitative, time-bound, achievable targets to address extreme poverty in its many dimensions: income poverty, hunger, lack of education, disease, poor child and maternal health, gender inequality, poor sanitation and environmental sustainability.

Many countries, notably in East and South Asia, have made substantial progress towards the Goals. Yet many others, and indeed entire regions, remain dangerously off-track. SubSaharan Africa is the most serious and persistent laggard, with food shortages, a rapidly expanding population, a crushing disease burden and environmental degradation combining to keep millions in extreme poverty. Other regions, such as the Middle East, Central Asia and parts of Latin America, have had mixed success, with great progress on some of the Goals and persistent inequalities in others.

As reports by the UN Millennium Project, the Commission for Africa, and many others have shown, the tools and knowledge exist to meet the Goals, as does the financing .provided rich countries meet their long-standing pledge to devote $0.7 \%$ of the gross national income (GNI) to official development assistance. The Monterrey consensus on development aid provides the right framework 
with its focus on improved governance, increased public and private investments, more and better development assistance, and free trade for long-term economic development. Yet with 2015 the deadline to meet the Goals, time is running out to get countries on track towards achieving them. The cost of failure in terms of lives lost, growing insecurity and accelerating environmental degradation is too high.

\section{Breaking through}

Encouragingly, the past year has yielded a series of breakthroughs, both in high-level global politics and on the ground, which are building up the momentum behind the Goals and give us cause for optimism. The rich world has made a series of commitments to provide financing at the scale needed to meet the Goals, while a number of initiatives on the ground have demonstrated, and continue to demonstrate, that scaled-up, targeted public investments can lead to development success in some of the poorest countries.

The key breakthrough in 2005 was the commitment of European Union donors to achieve the target of $0.7 \%$ of gross national product (GNP) in official development assistance by 2015. An intermediate benchmark of $0.56 \%$ of GNP in aid as of 2010 was also established. Encouragingly, the new (much poorer) EU member states committed to donating $0.33 \%$ of GDP by 2015. Following this landmark commitment, 16 out of 22 OECD donor nations have either achieved, or committed to a timeline for achieving, the ODA target of $0.7 \%$ of GNI by 2015 . The six remaining countries are Australia, Canada, Japan, New Zealand, Switzerland and the United States.

At Gleneagles in July 2005, the Group of Eight (G8) leaders made further commitments to scale up financing for the MDGs, specifically in Africa. An extra $\$ 25 b n$ in donor financing by 2010 was promised for subSaharan Africa alone. The G8 also agreed to forgive the debt of several of the poorest countries, and committed to ensuring universal access to anti-retroviral treatment for AIDS by 2010.

At the UN World Summit last September, world leaders committed to prepare national development strategies that are bold enough to achieve the MDGs. They also adopted several "quick-impact initiatives", designed to 
make rapid progress in many key areas: bed nets and medicines to fight malaria, antiretroviral medicines for AIDS, fertilisers for replenishing soil nutrients and launching the African Green Revolution, hardware and software for rural connectivity, and countless other practical steps that can relieve hunger, disease and isolation at relatively modest cost. These quick-impact initiatives are already proven to work, they are affordable and, importantly, their results can be easily measured and monitored. They now need to be implemented at scale.

\section{Implementation is gathering pace}

The key challenge now is implementation. Fortunately, we are also beginning to see progress on this front. Remarkable results have been achieved in some countries that have implemented large-scale national programmes to achieve the Goals. In Ghana, a public-private partnership, with support from the government of the Netherlands and Unilever, has launched a national school feeding programme for $1 \mathrm{~m}$ children using locally produced food. This programme is not only improving child nutrition and health; it is also boosting school attendance, improving educational outcomes and creating a market for locally produced food.

Another powerful example is the Measles Malaria Initiative, run by the Center for Disease Control, Red Cross Red Crescent, UNICEF and WHO, which has implemented national campaigns for measles vaccination and the free distribution of long-lasting insecticide-treated malaria bed nets. Extremely successful campaigns have been implemented, most recently in Niger and Togo, with many other African countries scheduled to follow in 2006 and 2007. The results include a sharp fall in the incidence of malaria and drastically lower measles ${ }^{2}$ importantly, their results can be easily measured and monitored. mortality. Perhaps most impressively, the ${ }^{2}$ Once empowered with the means, farmers campaigns lasted only a few days, were have more than tripled their crop yields implemented at an extremely low cost using and food output in a single season. School Red Cross Red Crescent volunteers, and attendance has soared in response to school achieved country-wide coverage. These feeding programmes and the elimination of and other programmes, such as the fertiliser user fees. Healthcare has 
been dramatically strategy currently being prepared by the bolstered through the provision of local government of Malawi, clearly demonstrate clinics and the mass distribution of long-the feasibility and success of national-scale lasting insecticidetreated bed nets to fight programmes to meet the MDGs. malaria. The initiative, which is partially funded by the government of Japan, covers

The Millennium Villages, a joint effort of the some 390,000 people in 12 sites across Earth Institute, UNDP, the UN Millennium subSaharan Africa . one for each major Project and Millennium Promise, are agro-ecological zone. The results so far are demonstrating that the MDGs can be met in impressive, and show that this approach can some of the poorest villages in sub-Saharan be taken to scale. It is time for official donors Africa through community-led development. to build on these results.

\section{Preparing MDG-based national strategies}

At the UN World Summit, every country was called upon to prepare an MDG-based national development strategy. Such a goal- based approach requires a major shift in thinking, away from the marginal expansion of services and infrastructure provision towards a long-term programming of public expenditures to achieve the outcome goals agreed in the Millennium Declaration.

Over five years after the adoption of the Millennium Development Goals, national strategies that are anchored in the Goals remain few and far between. Most Poverty Reduction Strategy Papers submitted for approval to the International Monetary Fund and World Bank reflect a shadow of what countries actually need to achieve the Goals.

Countries are still advised by development partners to continue on a business-asusual scenario by keeping their strategies in line with the limited resources and aid flows at their disposal. It is no wonder that the resulting strategies cannot deliver on the Goals. Governments are accused of incompetence, and sceptics feel vindicated in their view that the MDGs cannot be met.

Fortunately, several countries have begun to buck this trend. Ethiopia, Kenya, Senegal, Tajikistan and others have put forward the first MDG-based development strategies. 
Many other countries are approaching the UN for support in preparing rigorous strategies to achieve the Goals. Their leadership now needs to be recognised and reciprocated with bold support from the international community to permit the implementation of these strategies through a real international partnership.

Where available strategies fall short in terms of ambition, financing or analytical rigour, governments should be encouraged and supported in mapping out the practical investments needed to deliver basic infrastructure, ensure good health, promote education and gender equality, improve environmental management, and launch the African Green Revolution. Imperfect strategies should be improved instead of serving as a justification for inaction, as is still too often the case.

Fortunately, major strides are being made in Africa and elsewhere towards the integration of the MDGs into national budgets, development initiatives and poverty reduction strategies. NEPAD's African Peer Review Mechanism (APRM) is making important contributions towards strengthening governance across Africa. The fact that so many countries are voluntarily subjecting themselves to scrutiny by their peers exemplifies the strong commitment among African countries to fulfil their side of the Monterrey Consensus.

In May, African ministers and development partners met in Abuja for the Financing for Development Conference. The purpose was to transform the recent commitments for increased financing for African development into action, with specific focus on meeting the MDGs and developing coherent national strategies to do so. Britain's Chancellor of the Exchequer, Gordon Brown, delivered a powerful speech in which he reiterated the UK's commitment to providing $\$ 15 \mathrm{bn}$ over the next ten years in support of ten-year, costed education strategies. In response, 20 African countries announced that they would present national strategies to meet the 'Education for All' Goals at this September's annual meetings of the World Bank and IMF. Implementing these education strategies will be an important breakthrough in moving towards national-scale programmes to achieve the MDGs. 
Another area where African leaders are taking the initiative is the African Green Revolution. In response to the $\mathrm{UN}^{2}$

Secretary-General's call for an African Green Revolution in early 2004, NEPAD convened the Africa Fertiliser Summit in Abuja in June this year. Summit participants pledged to improve access to fertilisers, improved seeds and other key agricultural inputs through smart subsidies and strengthened private distribution networks. Malawi and many other African countries have already drawn up national strategies for agricultural inputs. These practical commitments hold the promise of greatly reducing poverty and hunger in rural Africa, and now need to be implemented.

Together, these breakthroughs over the past year show that the glass is half full. The international community now needs to build on the momentum behind the Millennium Development Goals by supporting governments in preparing and implementing practical strategies to meet each Goal. Needless to say, the IMF and World Bank play a critical role in supporting this process.

\section{The role of the IMF and World Bank}

In his April report on the IMF's mediumterm strategy, Rodrigo de Rato, the Fund's managing director, pledged to increase the organisation's engagement in low-income countries to achieve higher growth and to meet the MDGs. He called for an approach that assesses "if projected aid flows are consistent with macroeconomic stability and the estimated costs of achieving countries' development goals" and urged candour by informing "donors when there is scope for more aid to be absorbed and, conversely, when it judges that expected aid flows put macroeconomic stability at risk." Through this document the IMF has taken its boldest step yet in aligning its work in low-income countries with the Millennium Development Goals.

We see three areas in which the IMF and World Bank can, and must, go further in supporting the Goals. First, the World Bank should work with the UN system to support every developing country in estimating the financial and human-resource needs for meeting the MDGs. Second, the Fund needs to support the preparation of an MDG- 
consistent financing and macroeconomic framework. Next, the Fund staff should work not only with the finance ministers of the developing country but also their counterparts in donor countries to mobilise the needed financing.

In addition to the IMF and World Bank staff, their Executive Boards needs to review every country programme proposal for consistency with the MDGs. Standard checks applied to each programme should be whether the proposed level of financing is consistent with achieving the Millennium Development Goals and if the financing strategy is compatible with long-term economic growth and macroeconomic strategies.

By building on the Fund's medium-term strategy and taking decisive action toimplement these practical steps towards operationalising the MDGs, the IMF and the World Bank will make a critical contribution to sustaining and building on the accelerating momentum for achieving the Millennium Development Goals. The fruit of this labour will be many lives saved and a better world for all. 